\title{
Metaphyseal chondrodysplasia, Jansen type
}

INSERM

\section{Source}

INSERM. (1999). Orphanet: an online rare disease and orphan drug data base.

Metaphyseal chondrodysplasia, Jansen type. ORPHA:33067

Jansen's metaphyseal chondrodysplasia (IMC) is a very rare autosomal dominant skeletal dysplasia characterized by short-limbed short stature (due to severe metaphyseal changes that are often discovered in childhood by imaging), waddling gait, bowed legs, contracture deformities of the joints, short hands with clubbed fingers, clinodactyly, prominent upper face and small mandible, as well as chronic parathyroid hormoneindependent hypercalcemia, hypercalciuria, and mild hypophosphatemia. 